\title{
DESIGNING INTERFACE FOR INTERACTIVE MULTIMEDIA: LEARNER PERCEPTIONS ON THE DESIGN FEATURES
}

\author{
Geetha Udayangani Kulasekara (dgkul@ou.ac.Ik) \\ Buddhini Gayathri Jayatilleke (bgjay@ou.ac.lk) \\ The Open University of Sri Lanka, Nawala, Nugegoda, Sri Lanka \\ Uma Coomaraswamy (ucoom@ou.ac.lk) \\ Distance Education Modernisation Project, Narahenpita, Colombo 05, Sri Lanka
}

\begin{abstract}
Interactive Multimedia (IMM) package has a greater potential of supporting individual differences of learners due to its inherent strength of media attributes. This study was carried out to explore the design features of IMM, which was specially designed to support the open and distant learners, studying Microbiology as a part of the B.Sc. Degree program, of the Open University of Sri Lanka (OUSL), with the purpose of explaining the dynamic abstract concepts in Microbiology. When designing the IMM emphasis was placed on the design features, interface design in particular, in order to help the learners to achieve a meaningful learning experience. The purpose of this research paper is to explore learner perceptions of the design features of the IMM and, in developing a more user friendly, authentic instructional package. As such, quantitative and qualitative research methods were used by means of questionnaires, interviews and observations. Evaluation reveals many supportive and constructive outcomes, and suggests improvements in providing a better support for learners studying science subjects at a distance. In the context of the university using new technologies, especially for delivery, the results of this study would be a great asset.
\end{abstract}

Keywords: animation, interactive multimedia, learner perception, microbiology.

Open and distance learning has increased access to education globally, using various instructional strategies giving high priority to learner centeredness. In this system the learner is empowered to take greater responsibility for their own learning by incorporating a wider range of teaching methods. Therefore, Interactive Multimedia (IMM) technology scores exceptionally well having the strength of its media attributes supporting individual differences of learners by providing various learning experiences enabling them to achieve meaningful learning.

Interactive multimedia has a great potential as an effective instructional tool to use particularly on subject areas, which are difficult to visualize. An IMM was developed to support the distant learners, studying Microbiology as a part of the B.Sc. Degree program in the Faculty of Natural Sciences of the Open University of Sri Lanka (OUSL), with the purpose of explaining the dynamic abstract concepts which are hard to visualize in lengthy explanations in print based course material. At present, printed material is the core medium of teaching, supported by 
audio-video material. Great ingenuity and specialist expertise were used in developing the instructional material in print for effective teaching learning in microbiology (Coomaraswamy, 1999).

When developing the self-learning computer mediated teaching package at OUSL, the emphasis was placed on the instructional design, interface design in particular in order to help the learners to achieve meaningful learning experience. Interface designing is crucial, to produce an effective IMM, because the appearance of all display elements on the screen will affect how the learners will interact with the program. Therefore, careful attention has to be made, in designing educational software packages that will take the advantage of multimedia capabilities, without loosing the focus of the learner's attention or the content being presented.

The purpose of this research paper is to explore the learner perceptions of the design features of the IMM, which visualizes the complex, microbial processes that occur within bacterial cells, in developing a more user friendly, authentic instructional package. In order to address this, the study examined the following aspects: a) How useful were the user interface in helping students learn? b) How effective is the navigational design?

\section{THEORETICAL BACKGROUND}

Multimedia program is characterized by the presence of text, pictures, sound, animation and video; some or all of which are organized into some coherent program (Phillips \& Jenkins, 1997). An important part of any multimedia program is the 'interface', which is the communication boundary between the computer and the user. In order to communicate the program to the user it is primarily the computer screen and how it is designed is important; it can also include audio or other forms of output (Alessi \& Trollip, 2001).

Stemler (1997) highlighted the importance of screen design for multimedia developers. It should provide with effective instructions, navigational tools and visual aesthetics design should provide effective instructions, navigational tools and visual aesthetics (Milheim \& Lavix, 1992). 'Gaining attention' has been identified by Gagne (1985) as the first condition of learning in his "nine events of instruction". Therefore screen design plays a key role in "arousal of learners' interest and maintaining the interest throughout the learning process.

Use of carefully selected colour scheme is effective for attracting attention and motivating learning. It is recommended to use neutral greys or pastel colours to the background since it recede optically (Milheim \& Lavix, 1992), or cool colours as they create calm feeling (Phillips \& DiGiorgio, 1997). Referring to literature, Stemler, (1997) states eight recommended guidelines for using colours and it refers to use dark colour fonts on light backgrounds, use maximum of three to six colours and to be consistent in colour choice within program.

Text is the main mode of presenting information. Hannafin \& Hooper, (1989) report that, text on computer screens are read slowly by learners, and their comprehension is lower when compared to reading from a text page. Stemler (1997) states that people used to read computer screens $28 \%$ slower than reading textbooks. He also states to limit the quantity of information to a few items per screen and chunk the information using window overlays. As 
such, when designing computer display, important concepts selectively presented little at a time and the screen keep free of clutter, by using blank space between boundaries (Pellone, 1995). Some of the factors that influence textual communication are typeface, font \& style, text, animation and hypertext (Redid \& Mishra, 2003). Typeface are broadly categorized into two types, 'serif' and 'san-serif'. A number of authors (Phillips \& DiGiorgio, 1997, Redid \& Mishra, 2003, Boyle, 1997, Oliver \& Herrington, 1995), recognized that serif fonts should be used for body text and sans-serif fonts should be for headings. However, some other authors (Poncelet \& Proctor, 1993) identify that san-serif fonts work better on the computer screen than serif fonts.

Najjar (1998) said that pictures are more elaborate than text, and elaborate processing often leads to improvements in learning performances. Learning tends to be strongest when pictures supply redundant or supplement information that is unclear or incomplete (Jones, 1995).

Graphics communicate effectively (Jensen, 1997) and greatly enhances learning, especially for special relationship and for objects or procedures that can be visually depicted (Alessi \& Trollip, 2001). Najjar (1998) says that pictures are more elaborate than text, and elaborate processing often leads to improvements in learning performances. Learning tends to be strongest when pictures supply redundant or supplement information that is unclear or incomplete (Jones, 1995).

It is essential that the selective graphics reinforce the program's objectives (Phillips \& DiGiorgio, 1997) and when designing multimedia attention should be made to create all the graphics in colour and in high resolution to display accurate and sharp images (Pellone, 1995).

Most graphics can be animated to teach facts or concepts and demonstrate procedures. Animations are designed as a simulation of movement created by displaying a series of pictures or frames (Redid \& Mishra, 2003). Animations capture attention and provide dynamic explanations and demonstrations especially when illustrations otherwise impossible (Pellone, 1995). When designing animations Alessi and Trollip (2001) recommend in allowing the learner to pause, continue, repeat and in some cases control the speed of change.

Mayer (1997), observed that multimedia learners perform well when auditory explanations are combined with visual instructions. Alessi \& Trollip, (2001), states that, the sound is excellent for gaining attention even when the learner is distracted and even when not looking at the display. They also state that audio is also useful to inform the special directions in the display.

Where audio is used to support text, it is important to provide a way for the learner to pause and repeat the sound (Stemler, 1997). When designing audio, user-control is essential, thus the user should have access to play, pause, continue, volume control and replay (Alessi \& Trollip, 2001).

An important consideration when designing a multimedia is 'navigation', which in case define as how the students move through instruction and how the instruction is designed to facilitate understanding of the organization and structure of content (Weston, Gandell, McAlpine, \& 
Finkelstein, 1999). Herrington and Oliver (1997) state there are three purposes of navigation: (a) to allow students to locate and access particular information (b) to allow students to purposely move between relevant information (c) to allow students to determine the current position within the program. Navigation plan can be designed through hyperlinks from words/sentences/graphics or buttons for navigation (Redid \& Mishra, 2003). There are number of possible navigational schemes: linear, hierarchical, mixed hierarchical and concentric (Phillips \& DiGiorgio).

Interactivity is seen as one of the most important aspects of computer aided learning and refers to a feature, which actively involves and engages the learner (Kennedy, Petrovic, \& Keppel). Interactivity can be used effectively to empower students to take a more pro-active role in acquiring, analysing and synthesising information (Goldman \& Torrisi-Steele, 2002). Interactivity may take several forms such as: formative assessment questions on material covered, asking students to perform some manipulations of the interface, or challenging students to form predictions base on the material covered (Kennedy, Petrovic, \& Keppel, 1998). Formative assessments with feedback enhance retention of knowledge and remediation of incorrect knowledge (Stemler, 1997). Regarding designing of feedback questions Alessi \& Trollip, (2001) sate, instructions should be provided on how to respond to the question; learner should never forced to answer correctly to proceed; feedback should be constructive; feedback should not be misleading; feedbacks should be prompt.

\section{METHODS}

This section briefly discusses the design phase of the IMM, the sample, research methods including the types of data collection instruments, and the data analysis.

Design Phase - Documentation of the design phase was done, by creating the storyboards including all the instructional, navigational and interactive features required to include in each screen of the IMM. As such, the storyboards were incorporated with specification of text, audio, animations and navigation design. The instructional design was based on Gagne's (1985) nine events of learning.

Screen design was based on Phillips \& DiGiorgio (1997). A lighter color background was designed and appropriate dark colors were used for text (See Appendix-1). Careful consideration was made to use only 2-4 colours per screen. Basically brown blue, black and occasionally red colures were used for text. Both serif and san serif fonts were used and mostly those were the Batang, Bookman old, Century Gothic and Arial fonts. Small chunks of text were used without cluttering on the screen having hyperlinks to go deeper into the subject

A mixed-hierarchical navigational scheme by Phillips \& DiGiorgio (1997) was adapted to design the navigation. A content page was designed as the main centre for navigation having seven numbered buttons in front of the heading (See Appendix-1). Content page was also incorporated with a Menu button including objectives, glossary, index and references; and with an Exit Button Inner screens (pages) were also included with the same navigational buttons and placed along the left margin allowing access to any screen from the existing screen. The buttons were designed with a 3-D appearance and the existing screen was portrayed with a 
'push down' state of the button. All the buttons were incorporated by 'tool tips' to make students are aware of the name of the screen which links that button. The bottom line of each screen was used to place the Self Assessment Questions (SAQs), Glossary and Exit buttons. Within the page, hyperlinks were introduced to go into inner screen/pages.

Graphical illustrations of bacteria depicting the nuclear material with different colours were used to emphasis the text explanations. Animations were designed to explain the dynamic bacterial genetic processes, heightening the impact of presentations. Those animations were incorporated with play, stop and repeat buttons allowing students to view as they wish. All screens except Glossary and SAQs were coupled with a background narration having 'stop' and 'play' audio buttons on the top left corner of each screen (See Appendix-1).

As a pedagogical feature, a glossary and an SAQ were designed. To assist the learners to overcome the language barrier, a glossary was incorporated. Glossary was designed in such a way that learner can click the letter and get the desired word starting from that letter. Each section was incorporated with an SAQ button, which links to a screen having a number of selfassessment questions aligning with the learning outcomes. These questions were designed in such a way to display prompt feedback, once the user makes a selection

Software-This IMM was produced using the authoring tool, Macromedia Director. It enables the creation of a fully self-contained, self-running program of multimedia and web base productions (Gross \& Robert, 2001).

Sample - The quantitative study was conducted with 42 science undergraduates. The first 30 students were also interviewed and observed in order to gather qualitative data.

Research Methods - Both qualitative and quantitative methods were used to collect data. Quantitative data collection was done with the aid of a questionnaire, while observations and interviews were conducted to gather qualitative information. Triangulation of research methods was used to validate the results.

The questionnaire comprised of open and close-ended questions. The interview schedule consisted of standardized open-ended questions to get feedback while each interview was also recorded. The observational study was carried out using an observational schedule. In this instance researchers adopted a passive non-intrusive role as pointed out by Cohen, Manion \& Morrison, (2000) in order to observe students without interfering their learning.

Content analysis was carried out with qualitative data and frequencies were computed for quantitative data.

\section{RESULTS}

\section{Screen design}

Students have found that the screen design is comfortable to the eye and user friendly in moving through the lesson. Background with a lighter colour textured background was 
preferred over the plain background. They also claim that the text and graphics per screens are in proper balance. Students have emphasised this fact in the questionnaire data, by giving a cumulative of $100 \%,(60 \%$ agreeing and $40 \%$ strongly agreeing) saying that various media used in screens complement each other. Students especially valued the limited amount of information included per screen. When the questionnaire asked about whether the content is broken into units that are small enough to be readily learned, a cumulative of $91 \%$ of them agreeing (39.50\% agreeing and $51.30 \%$ strongly agreeing) and only $6 \%$ disagreed asking to reduce the units further. During interviews it was also revealed that text in each screen are not crowded or cluttered:

"I have learned all these by studying course material. But here it is displayed on the screen in a simple clear manner...everything is laid in front of my eyes, in a very short period of time and I was able to recap the concepts in a firmer grasp.... Not like in a textbook, the limited number of information given in a specific screen, induce me to go to the next page seeking for more information. Studying like this is not boring'. (S25/F)

However, some students suggested reducing the text content on one of the screens viz. 'bacterial genetic make up'. On the other hand, some students claim that it is better to incorporate some more explanations using text in screen on 'conjugation'.

It was also revealed that the 'contents page' of the IMM is simple and clear. Commenting on the design of the inner pages, students preferred the existing layout with the buttons on the left side of the screen. Also they preferred the placement of the media elements such as the audio buttons, graphics, text and animations on the screens. Some students suggested the idea of an optional 'auto run' button.

Observational study witnessed, several students miss viewing the 'objectives' under the menu option on the content page. While interviewing when they were inquired about the miss viewing, they preferred to have the 'objectives' also on the same list of buttons of the 'content' page.

Almost all students commented on the existing fonts of the IMM programme during the interview. Most of them were happy with the serif fonts used ('Bookman') in the programme saying that these are quite legible and clear on the screen and they did not find difficulty when reading on the screen. Questionnaire data also supported having $54.77 \%$ agreeing and $33.33 \%$ strongly agreeing (a cumulative of $88 \%$ ) that the written texts on screens are easy to read. However, $11.99 \%$ of students disagreed to the same fact and it was revealed at the interview that, they were not happy with the sans serif font ('Century gothic') font that was used in certain parts of this IMM. Those who opposed of this font suggested to have it in bold face if use the same font 'Century Gothic'. One student (S3/M) explaining his views:

'The font type used in the 'plasmid' section (Century Gothic font) is difficult to read. I found it difficult to differentiate ' $U$ ' and ' $V$ ' in that.' (S3/M) 
From the interview data it was also emerged that most of the students were satisfied with the existing font size on the display screens while some others claimed to have bigger fonts especially in 'animations' where labelling or explanations were included.

Colours used for text, explaining the content were very much appreciated by the students. They also commented that it is attractive and helped them enthusiastically move with the lesson.

Students also felt happy with the colour of the background especially as it is a lighter colour one. Especially the colour combination blue and brown used on this screen was specifically valued by the students. However, students have found difficulty in reading the red colour in this background especially used in the top statements of SAQs. (S7/M) and (S11/F) expressing their views:

'Lighter colour background is good and text is better visualised in this background. The blue and brown text colours better suited to this background. But red colour text is not very much visible enough to read on this background Pictures are really good with different colours, and it is easy to differentiate the microbial parts and understand the processes well with different colours in the graphics.' (S7/M)

Students compared the colourful graphics in the IMM with that of the black and white pictures in the course material and expressed their enthusiasm in learning. They also expressed that the bacterial cell components depicted in different colours gave them a better communication of concepts of bacterial genetics. Questionnaire data also supports having a cumulative percentage of $100 \%$ (23.77\% agreeing while $76.33 \%$ strongly agreeing) with the view that coloured graphics stimulated their learning. Further, they explained that they could grab concepts very quickly as the colour discrimination used in animations, visualises the process very clearly. (S6/F) explaining her enthusiasm:

'I never felt monotony in studying this IMM with the colourful graphics, animations and text, coming time to time on to the screen, and I was highly engaged in the learning process with these features.' (S6/F)

\section{Graphics}

Students expressed their views on the quality of the graphics used in the IMM. They have perceived that the graphics are attractive, comfortable to the eye and are of professional looking. Graphics have created a clear visual communication and have catered for their styles of learning. S7/M expressing his ideas:

'I can learn more with pictures than text. It helps my way of learning having more picture descriptions than text.' (S7/M)

Almost all students were highly motivated with the bacterial picture descriptions; and those have communicated the subject matter well. They have observed that, what is explained in the lesson is emphasised more with graphics. Every student was with the view that they were 
more comfortable to learn with graphics rather than lengthy descriptions. They also added that graphics help them to retain and recall the microbial descriptions easily than studying with text. One student mentioned this aspect:

'Some concepts explained in length in course material can be understood easily with visuals. Therefore, this IMM makes one to study easily with a shorter period of time. Sometimes the printing quality of our course material is not so good and therefore the pictures are not so clear. But here, they are in colour pictures and the resolution gives good colour contrast so that it is easier to grasp. (S25/M)

Most of the students were requesting to add actual natural photographs or electron micrographs of bacteria rather than drawn diagrams. Few students also requested to incorporate motion into bacteria rather than static, to give them a live appearance.

\section{Animations}

Students have acquired animations as one of the most helpful features in learning the abstract concepts in this IMM. They were of the view that the animations are clear and pleasing to their eyes. As the 'play' and 'stop' buttons were built into animations, students have visualised the animations several times as they wish, until they properly understand the process.

Observational studies also provided evidence on the students' repeated engagement with animations using the 'stop' and 'play' buttons.

Students' feedback also revealed that they have grasped the abstract concepts of bacterial genetic processes well with the incorporation of these animations. They expressed that animations visualised the processes as live processes, which cannot even be explained in face-to-face situations. Questionnaire results also verified this fact having $81 \%$ strongly agreeing and 19\% agreeing (a cumulative of 100\% agreeing) on the helpfulness of animations in learning genetic processes in microbiology. Further during the interviews, students highly valued the importance of having background narration to the animations. Students have felt that, they were studying in a classroom situation, having an audio narration in the animations, and accepted it an excellent facility in ODL Students explaining their views on learning with animations:

'Since the animations are with narrations, I felt it like somebody explaining the process like we are in a face-to-face situation. (S2/F).

'Hfr conjugation' and 'specialized transduction', were very clearly explained in this, which was very difficult to study from the course book. All the doubts that I had with 'excisions' and in 'conjugation' were clearly clarified with once watching this IMM. (S11/F).

\section{Audio}

Commenting on the audio narration that is used in the IMM, almost every student said that audio narration is simple, clear and understandable. They also said that it is at a moderate speed, which is understandable to them. As a whole, students were happy with the existing male voice that is in the audio narration. However, when they were asked how they would like 
it to be improved, some students requested to incorporate male and female voices both. It was interesting to note that female students requested a young male voice while male students preferred a female voice to be incorporated.

All the students highly valued the audio narration as it helps them to pronounce the technical terms properly, unless otherwise they have mis-pronounced the terms only by reading the course material. As such, they also revealed that the narration of the same text written on the screen is useful. From the observational studies also it was found that while listening to the audio, students were silently reading the text by moving the cursor along the text lines.

They also valued having the 'on/off' audio button, as it allowed them to listen to the audio repeatedly. While if they do not want it, turn it off and do a silent reading. This fact also observed from the observational studies; some of the students used to listen to the narration while reading the text, while some other students were not very keen on reading but used to listen to the audio repeatedly. Students explained their views on this at the interviews and said that narration has allowed them to concentrate more on what is on the screen and some students have found that it is easy to understand the concepts by listening rather than reading. Questionnaire results also support this, by having a $67 \%$ strongly agreeing while the other $33 \%$ agreeing to the support given by audio in learning. (S7/M) explaining his view on audio:

'In Open and Distance Learning, listening process for learning is very little. It takes a lot of time to read the course material. But these audio narrations in this IMM help self learning better without a teacher.' (S7/M)

Students have also found audio as a helpful feature especially when learning with computers:

'It is very difficult to keep reading over and over specifically on computers, so that narration helps us in such occasions.' (S18/F)

It was also revealed that they felt comfortable by not having the audio narration for SAQs. As such they could have read silently the questions and think of the answer without any disturbances. Students' deep involvement in reading the SAQs was also witnessed by the observations.

Some students suggested incorporating an 'audio-bar' as it allows them to check how much more that they have to listen to. They also requested to incorporate a 'pause' button, so that it helps them think after listening for a while. Several students were requested to have an optional audio button having a soft music.

\section{Navigation}

Interview data revealed that almost all students have navigated easily with the IMM and no students have reported any negative aspects of navigation.

Questionnaire data on the navigational aspects of the IMM strongly supported the above fact. A cumulative of $96 \%$ (38\% agreeing and $58 \%$ strongly agreeing) of the students were with the 
view that it is very easy to navigate within the IMM lesson. When they were asked whether they got lost in the program while navigating in the lesson, accumulative of $97 \%$ disagreed (32.35\% strongly disagreeing and $64.6 \%$ disagreeing) depicting an effective navigation. A cumulative percentage of $94 \%$ (61.1\% agreeing and $33.83 \%$ strongly agreeing) were with the view that they were able to progress within the IMM at a comfortable speed. This was also witnessed at the observational studies, as every student moved confidently with IMM using the existing navigational support. Exclusive of any external support, they used it for the very first time without getting lost in the program.

Students felt that the 'tour guide' as a very helpful feature, which make them familiar to move through the lesson. Observational studies also evident that all students viewed the 'tour guide' option at the very beginning, as they were asked by the program.

This was strongly supported by the questionnaire data having a $100 \%$ of the students accepting (55.55\% agreeing and $44.44 \%$ strongly agreeing) the helpful support they gained by the 'tour guide' option to move about the IMM. One student (S26/F) explaining her views on the navigational aspect of IMM:

'Navigation is very clear with buttons, hyperlinks and also with commands saying 'click here' and so on. Also in the 'tour guide' it includes everything about how to move and familiarise the user on buttons, so that navigation help is perfect. I think even a person who does not know much about computers could easily use this IMM with this navigational design.' (S26/F)

Students found the navigation very simple and it has made even less computer literate students to study the lesson without any obstacles.

'My knowledge on computers was very poor. I even did not know how to use the mouse. But I could go through this IMM with little help. I moved with the lesson very well. This experience gave me lot of confidence to study with IMM. This multimedia lesson is properly designed to navigate throughout the programs. (S28/F)

\section{Interactive Pedagogical elements}

Glossary was one of the interactive features built into this IMM. Students expressed their pleasure in using the Glossary as it allows students to access the description of the terms as quickly as possible. They compared the easiness of accessing it with that of the glossary in the course material. Students expressing their view about the Glossary:

'Glossary is a very helpful feature in this multimedia lesson because with one 'click' of a button I could get the meaning or the clarification of a term; it was so quick. In microbiology we get lot of new words as we study. Having a glossary design in this way is very useful because to refer it we need a very short time when compared to the textbook.' (S15/M)

The assistance provided by glossary to help students understand difficult terms was well supported in questionnaire with a cumulate of $100 \%$ strong support having $67 \%$ agreeing and $33 \%$ strongly agreeing. Questionnaire data also revealed that $75 \%$ preferring a background 
narration for the glossary while $25 \%$ disagreeing having a background narration to the glossary terms.

Self-Assessment Questions (SAQs)- Students commented about the SAQs with prompt feedback with much excitement. Designing SAQs for each an every section was highly valued by the students. From the interview it was found that students were satisfied with the design features of the question and the feedback with right $(\sqrt{ })$ or wrong $(X)$ signs.

'SAQs at each end of the section made me actively go though the lesson. When we scored wrong at SAQs we could have gone back to the lesson to verify immediately. Also when we 'clicked' a correct answer there is the right sign and feedback says 'very good' with the description. This made me happy and motivated and also built confidence in studying. Because of the SAQs I could have moved to the next section with a clear and confident mind.' (S22/F)

However, most of the students have found that the colours used in the 'questions number button' and the introductory statement describing the question as not very legible to them.

\section{DISCUSSION AND CONCLUSION}

Screen design with the existing background, colours, text and graphics were well perceived by the students and the screen design has contributed in increasing their motivation to learn throughout the program. This fact supports the Gagne's 'gaining attention' in instructional design. Specifically in the existing screen design, students were attracted (a) to the colour scheme used in the overall screen design, (b) proper balance of the text and graphics in the screen design and (c) to the limited amount of information presented per screen.

Colours used in screens design have effectively grabbed students' attention. Dark colour text on the light colour background was appreciated by students (Stemler, 1997); especially the light colour background has created a pleasing sensation to them. Colours have supported students to distinguish between different structural information (Pellone, 1995) and highlighted the specific movements in genetic processes.

The researchers of this study specifically used the font 'Century Gothic' in text designing, since its close resemblance in shape to 'Sinhala' and 'Tamil' fonts, which are more circular. Although some authors (Poncelet \& Proctor, 1993, Faila, 2000) recommended sans-serif fonts for the body text of computer screens, students have found difficulty in reading the 'Century Gothic' in particular, which is a sans-serif font. Students have perceived the serif fonts more readable.

Limited amount of information allocated per screen has motivated students to go deeper in to the program and it has engaged them in active processing of related information. This has also supported by Stemler (1997) in chunking the information using windows overlays.

This study also shows students' attraction towards visual descriptions of bacterial genetic information, and they have effectively interacted with the subject matter within a very short period of time. Graphics have helped students to learn effectively than text as pictures have 
more features available for processing than do words (Najjar, 1998, Jensen, 1997). A similar study carried out at OUSL also supports students' preference to visual learning (Jensen, 1997). Texts are "verbal symbols" and they are the most abstract of Dale's Cone of Experience. A newer form of media such as multimedia is near the bottom of Dale's Cone approaching "direct purposeful experiences" - the most tangible mode of learning

Animations, have played a major role in presenting dynamic and abstract information about the gene transfer and genetic recombination mechanisms of bacteria; and students have perceived animations as the most helpful feature in learning these concepts and build up their enthusiasm in learning. It is generally accepted that animations can offer subtle benefits like heightening key information, heightening student interest and facilitating recall (Stemler, 1997). Supporting the same fact, Laurillard (2002) also identified animations as a medium for representing complex relationships.

Audio narration used in the IMM has acquired by students in various ways. It has helped them to learn the correct pronunciation; thus facilitating with the 'listening' component, which is more or less lacking in ODL situations. Concentrating on text while listening is supported by the explanations by Kalyuga, Chandler \& Sweller (2000), as the amount of information that can be processed using both auditory and visual cannels may considerably larger than using only one single channel. Thus, limited working memory may be effectively expanded by using more than one sensory modality (Kalyuga, Chandler, \& Sweller, 2000). Learners always benefit by having repeat option with the 'play' and 'pause' audio, buttons; and the study highlighted the lack of 'pause' option as a negative feature. Students claimed that having a 'pause' button would allow them to think before they proceed or to study unfamiliar terms and surfaced the importance of including it. Some students have preferred learning by listening rather than reading. Research information states that students with undeveloped reading skills will be more benefited by listening rather than reading (Stemler, 1997),. As such, audio component is of advantageous to these students who are non-native English speakers to learn the subject with foreign language. Having perceived animations with explanatory narrations as learning in a classroom situation with a teacher, it has created 'immediacy', which is the measure of psychological distance that the communicator puts between him and the object of his communication (Gunawardana, 2004).

The navigational design of the IMM was very well taken by even the less computer literate students. Navigational design use, has maximized the learner control providing the ability to navigate through the program at their own pace and ability level. Learner control is central to the design of instructions, and it promotes satisfaction and makes them take responsibility for their own learning (Stemler, 1997). The consistent and clear navigational system has allowed students to move without any confusion and disorientation within the IMM [15]. Pedagogical elements such as, interactive SAQs, glossaries and other synchronized media components have allowed students to actively process instructions. The feedback provided on the success of performing problems as described by Gagne (1985) in his seventh event of learning, has established reinforcement of appropriate performance and prevent further inappropriate performance. Inclusion of interactive elements, reinforce students to reflect on the content of 
instruction and encourage the integration of knowledge and elaborate on of new information with pre existing knowledge (Kennedy, Petrovic, \& Keppel, 1998).

However, a major drawback in designing instructions was surfaced from this study: viz. on the positioning of 'objectives' in the IMM. Having considered the importance of informing the learners, of the lesson objectives (Gagne, 1985), the objectives were placed in the 'Menu option' with the intention that students would view them first. However, this study revealed that objectives should be placed on the 'contents' page explicitly along with the main topics rather than having it separately at the beginning as a "menu button".

In conclusion, the design features used in the IMM has played a crucial role, as the entire learning process of the learner depends on how these features are designed: to engross learner, to trigger multi-sensory actions of the learner, to provide connections and to promote individualized learning in achieving meaningful learning. Findings of this research study may be a great asset to instructional designers and educational developers who are involved in the field of computer mediated instructions.

\section{REFERENCES}

Alessi, S.M. \& Trollip, T.R. (2001). Multimedia for learning: Methods and development (3rd ed.). Massachusetts: Ally and Bacon.

Boyle, T. (1997). Design for multimedia learning. London: Prentice Hall.

Cohen, L., Manion, L., \& Morrison, K. (2000). Research methods in education (5 $5^{\text {th }} \mathrm{ed}$.). London: RoutledgeFalmer.

Coomaraswamy, U. (1999). Ensuring quality in distance education: Development of instructional material in microbiology under the Department for International Development (DfID) UK Project. OUSL Journal, 2: 44-64.

Faiola, A. (2000). Typography primer. Pittsburgh, PA: GATF

Gagne, R.M. (1985). The conditions of learning and theory of instruction (4th ed.) New York: Holt, Renhart, and Winston.

Goldman, J.D.G. \& Torrisi-Steele, G. (2002). Constructivist pedagogies of interactivity on a CD-ROM to enhance academic learning at a tertiary institution. International Journal of Educational Technology, (November, 2002)- v3,.nl [ISSN 1327-7308].

Gross, P. \& Robert, J. (2001). Director 8, Demystified: The official guide to Macromedia Director, Lingo and Shockwave. Berkeley, CA: Peachpit Press.

Gunawardana, C.N. (2004). Designing the social environment for online Learning: The role of social presence. In D. Murphy, R. Carr, J. Taylor, \& T. Wong (Eds), Distance education and technology: Issues and practice. Hong Kong: Open University of Hong Kong Press.

Hannafin, M.J. \& Hooper, S. (1989). An interactive frame work for CBI screen design and layout. Computers in human behaviour, 5 (3), 155-165. In L.K. Stemler, (1997). Educational Characteristics of Multimedia: A literature Review. Journal of Educational Multimedia and Hypermedia, 6 (3/4), 339-359.

Herrington, J. \& Oliver, R. (1997). Multimedia, magic and the way students respond to a situated learning environment. Australian Journal of Educational Technology, 13 (2), 127-143. 
Jayatilleke, B.G. (2002). Sri Lankan students' perceptions of learning from a biology CD-ROM produced by the British Open University. In the proceedings of the $16^{\text {th }}$ Asia Association of Open Universities annual conference Nov 5-7, 2002, Seoul, Korea.

Jensen, E. (1997). Completing the puzzle: The brain-compatible approach to learning. Del Mar, CA: The Brain Store.

Jones, M.G. (1995). Visuals for information access: A new philosophy for screen and interface design. (ERIC Document Reproduction Service No. ED 015 675) In L. K. Stemler, (1997). Educational Characteristics of Multimedia: A literature Review. Journal of Educational Multimedia and Hypermedia, 6 (3/4), 339-359.

Kennedy, G., Petrovic, T. \& Keppel, M. (1998). The development of multimedia evaluation criteria and program of evaluation for computer aided learning. ASCILITE Conference.

Kalyuga, S., Chandler, P. \& Sweller, J. (2000). Incorporating Learner Experience Into the Design of Multimedia Instruction. Journal of Educational Psychology, 92(1), 126-136.

Laurillard, D. (2002). Rethinking university teaching: A conversational framework for the effective use of learning technologies. London and New York: RoutledgeFalmer.

Mayer, R.E. (1997). Multimedia learning: Are we asking the right question? Cambridge: Cambridge University Press.

Milheim, C.L. \& Lavix, C. (1992). Screen design for computer based training and interactive video: Practical suggestions and overall guidelines. Performance and Instruction, 3 (5), 13-21.

Najjar, L.J. (1998). Principles of Educational multimedia user interface design. Human Factors, 40 (2), 311-323.

Oliver, R. \& Herrington, J. (1995). Developing Effective Hypermedia instructional materials. Australian Journal of Educational Technology, 11 (2), 8-22.

Pellone, G. (1995). Educational software design: A literature review. Australian Journal of Educational Technology, 11 (1), 68-84.

Phillips, R. \& DiGiorgio, A. (1997). Design. In R. Phillips, The developer's handbook to Interactive Multimedia: A practical guide for Educational Applications. London: Kogan Page.

Phillips, R. \& Jenkins, N. (1997). Interactive multimedia development. In R. Phillips, The developer's handbook to Interactive Multimedia: A practical guide for Educational Applications. London: Kogan Page.

Poncelet, G.M. \& Proctor, L.F. (1993). Design and development factors in the production of hypermedia based courseware. Canadian Journal of Educational Communication, 22 (2), 91-111. In L. K. Stemler, (1997). Educational characteristics of multimedia: A literature review. Journal of Educational Multimedia and Hypermedia, 6 (3/4), 339-359.

Redid U.V. \& Mishra, S. (2003). Educational multimedia: A handbook for teacher - developers. New Delhi: The Commonwealth Educational Media Centre for Asia.

Stemler, L.K. (1997). Educational characteristics of multimedia: A literature review. Journal of Educational Multimedia and Hypermedia, 6 (3/4), 339-359.

Weston, C. Gandell, T., McAlpine L. \& Finkelstein, A.(1999). Designing instruction for the context of online learning. The Internet and Higher Education, 2 (1) 35-44. 


\section{APPENDIX 1}

Screen Cast 1 - Contents page of the IMM package

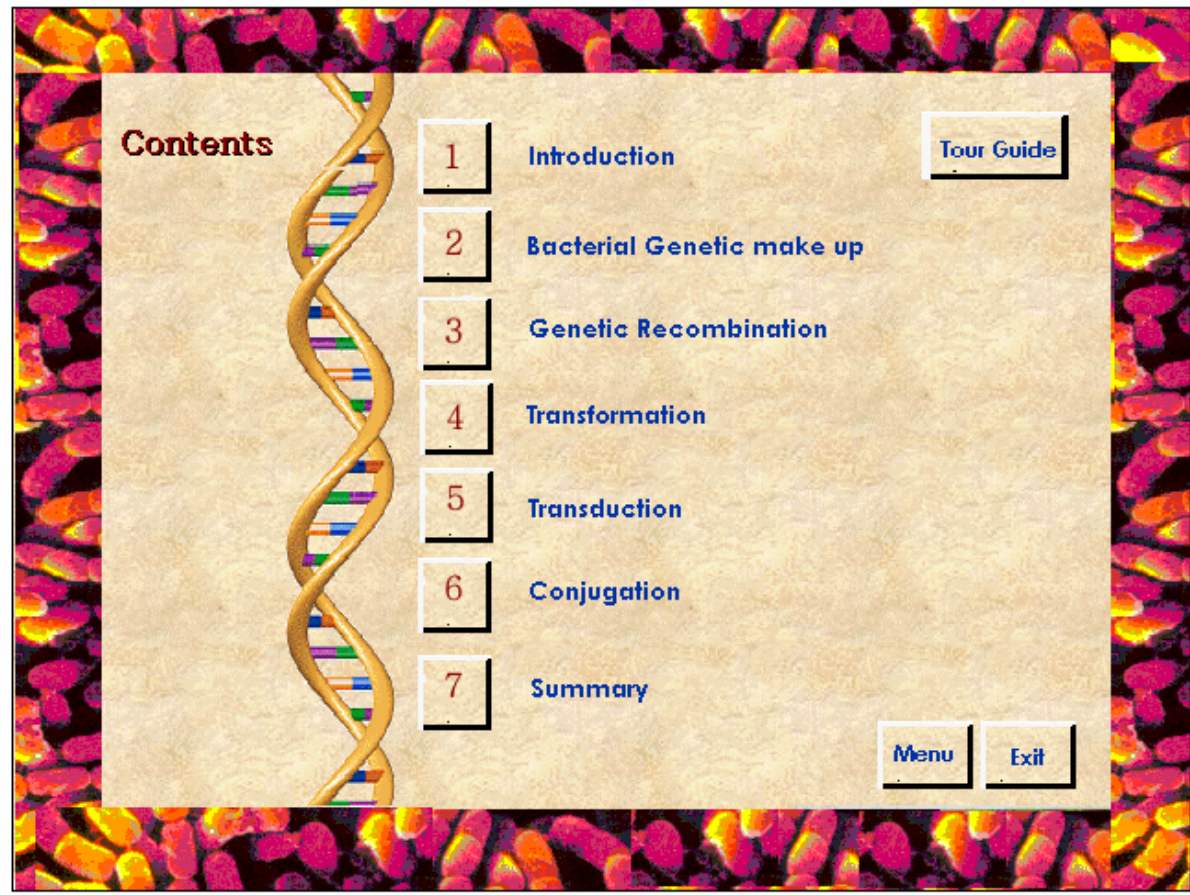

Screen Cast 2 - Inner page of the IMM package with hyperlinks and buttons

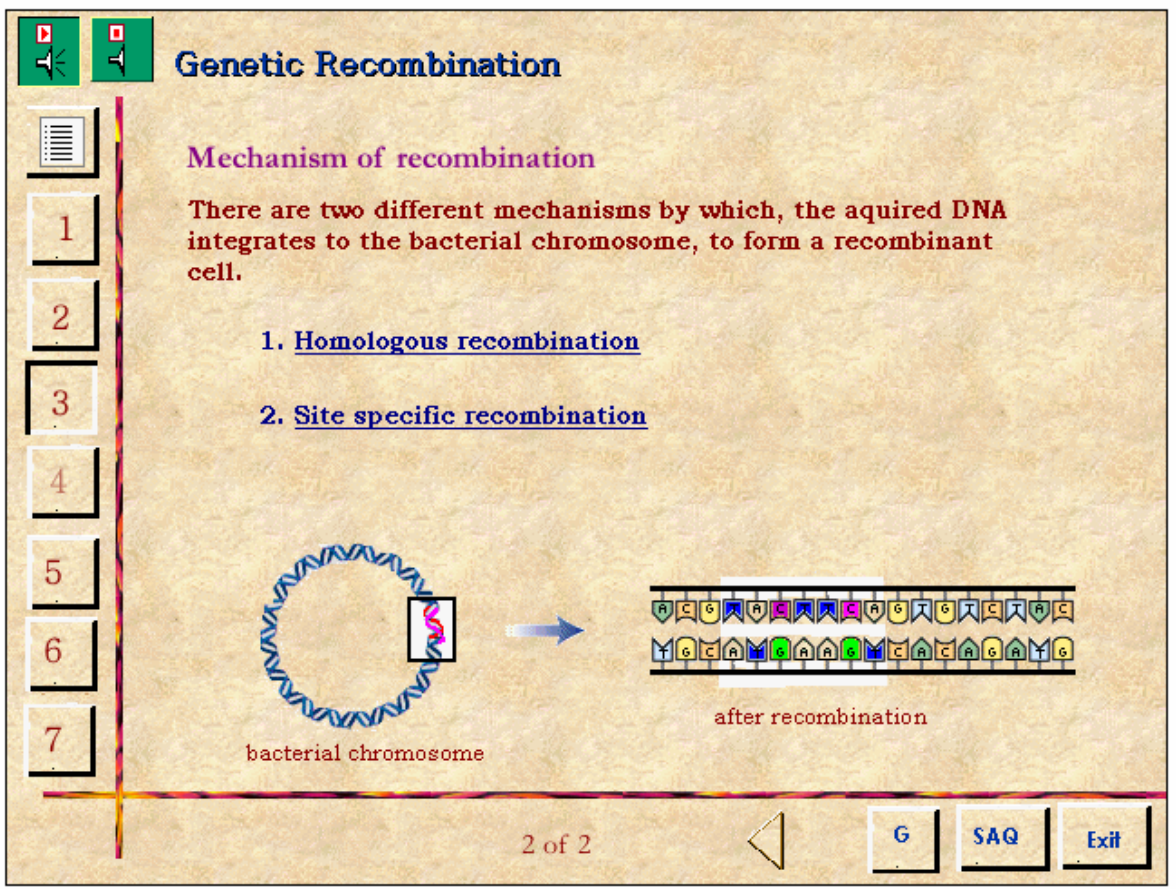




\section{Screen Cast 3 - Inner page of 'Screen Cast 2' linking to an animation}

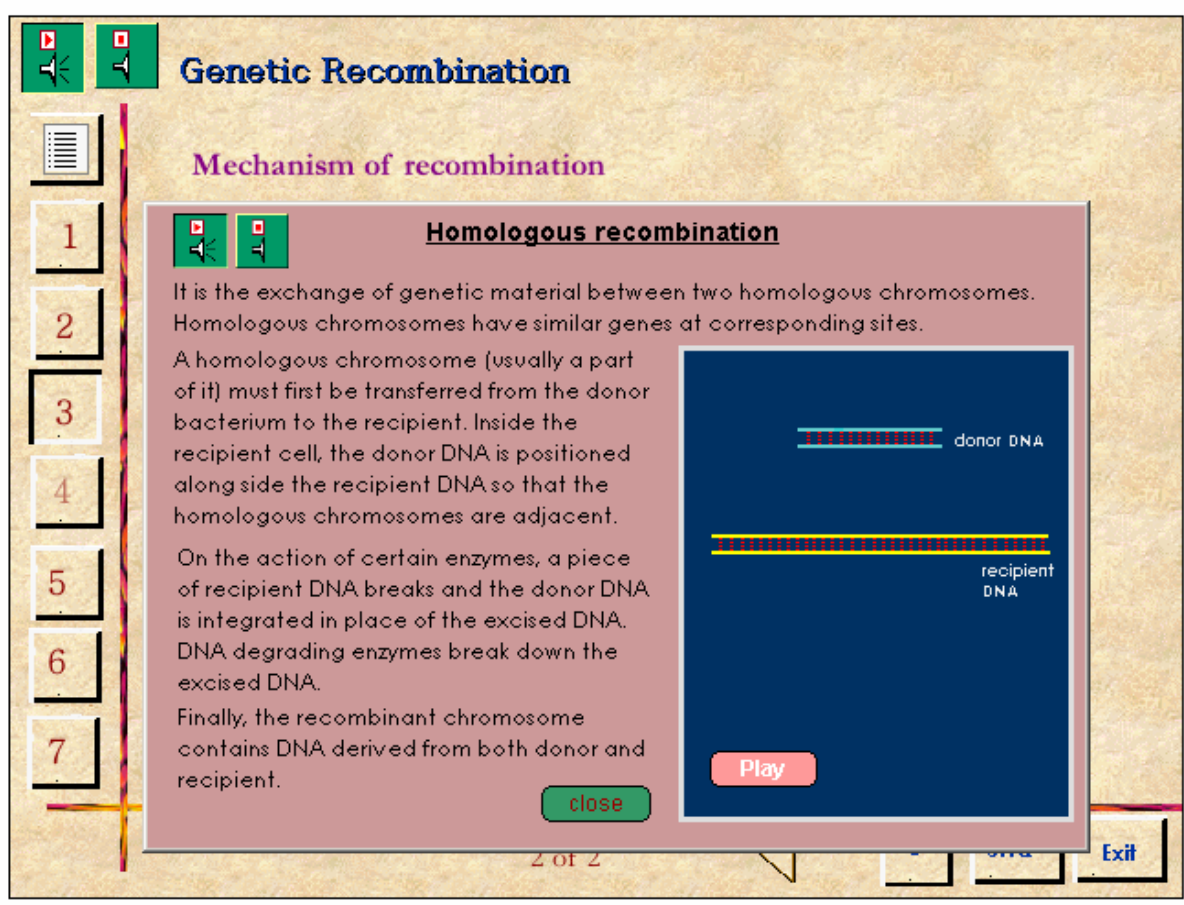

